\title{
PENGARUH KOMPETENSI ASUHAN KEBIDANAN KOMPLEMENTER MASSAGE PUNGGUNG TERHADAP INTENSITAS NYERI IBU BERSALIN
}

\author{
Kadek Ayu Suarmini ${ }^{1}$ Ni Made Karlina Sumiari Tangkas ${ }^{2}$ \\ ${ }^{1}$ Dosen STIKES Buleleng \\ 2 Dosen STIKES Buleleng \\ karlina.sumiari@gmail.com
}

\begin{abstract}
ABSTRAK
Pendahuluan : Nyeri persalinan dapat menyebabkan ibu lebih memilih alternative persalinan lain untuk menghindari nyeri persalinan melalui Persalinan Sectio Caesarea. Menurut World Health Organitation, standar rata-rata sectio caesarea disebuah negara adalah sekitar 5 $15 \%$ per 1000 kelahiran di dunia, rumah sakit pemerintah rata-rata $11 \%$, di rumah sakit swasta bisa lebih dari $30 \%$. Adapun saat ini, permintaan sectio caesarea di sejumlah negara berkembang melonjak pesat tiap tahunnya. Dalam persalinan, massage secara lembut dapat membantu ibu lebih rileks dan nyaman selama persalinan karena massage merangsang tubuh melepaskan senyawa endorphin. Berdasarkan hasil studi pendahuluan yang dilaksanakan di PMB Putu Putrini, A.Md.Keb, peneliti memperoleh data pada bulan Januari 2019 terdapat ibu bersalin primigravida sebanyak 25 orang. Hasil wawancara dengan 10 orang ibu bersalin, sebanyak 7 orang mengatakan nyeri semakin berkurang apabila diberikan sentuhan/pijatan pada punggung oleh keluarga yang mendampingi, sebanyak 3 orang tidak suka diberikan pijatan pada punggung karena tidak nyaman jika disentuh. Metode : Penelitian ini menggunaan desain penelitian Quasi Experiment dengan rancangan penelitian One Group pre-test dan post-test design. Hasil : Teknik massage punggung sangat efektif dalam menurunkan tingkat nyeri persalinan primigravida di PMB Putu Putrini dengan nilai $\mathrm{p}=0,00$ $(\mathrm{p}<0,05)$ yang artinya $\mathrm{p}$ value $<0,05$, sehingga hipotesa nol ditolak dan hipotesa alternative dalam penelitian ini diterima. Bidan juga memeliki kompetensi terkait dengan pemberian asuhan sayang ibu melalui sentuhan/pijatan kepada pasien sehingga dapat mengurangi nyeri. Kesimpulan : Ada perbedaan yang signifikan antara sebelum dan sesudah diberikan massage punggung terhadap pengurangan intensitas nyeri pada ibu bersalin primigravida di PMB Putu Putrini, A.Md.Keb dengan hasil uji p-value didapatkan hasil $(\mathrm{p}<0,05)$.
\end{abstract}

Kata Kunci : Massage, Nyeri, Ibu bersalin

\section{ABSTRACT}

Introduction: Labor pain can cause the mother to choose other alternative births to avoid labor pain through Caesarean Sectio Labor. According to World Health Organitation, the average standard of sectio caesarea in a country is around 5-15\% per 1000 births in the world, government hospitals averaging $11 \%$, in private hospitals it can be more than $30 \%$. As for now, demand for sectio caesarea in a number of developing countries is increasing rapidly each year. In labor, gentle massage can help the mother to be more relaxed and comfortable during labor because massage stimulates the body to release endorphin compounds. Based on the results of a preliminary study conducted at PMB Putu Putrini, A.Md.Keb, researchers obtained data in January 2019 that there were 25 primigravida birth 
mothers. The results of interviews with 10 maternity mothers, as many as 7 people said the pain is reduced if given touch / massage on the back by the accompanying family, as many as 3 people do not like being given a back massage because it is uncomfortable when touched. Method: This study uses a Quasi Experiment research design with One Group pre-test and post-test design research designs. Results : Back massage technique was very effective in reducing the pain level of primigravida labor in PMB Putu Putrini with a value of $p=0.00$ ( $p<0.05$ ), which means $p$ value $<0.05$, so that the null hypothesis was rejected and the alternative hypothesis in this study be accepted. Midwives also have competencies related to the provision of maternal care through touch / massage to patients so as to reduce pain. Conclusion : There was a significant difference between before and after a back massage was given to reduce the intensity of pain in primigravida in PMB Putu Putrini, A.Md.Keb with the $p$-value test results obtained $(p<0.05)$.

Keywords : Massage, Pain, Maternity

\section{PENDAHULUAN}

Persalinan dan kelahiran merupakan kejadian fisiologis yang normal. Persalinan dan kelahiran normal adalah proses pengeluaran janin yang terjadi pada kehamilan cukup bulan (37 42 minggu), lahir spontan dengan presentasi belakang kepala yang berlangsung 18 jam, tanpa komplikasi baik pada ibu maupun pada janin (Prawirohardjo, 2013). Seorang wanita yang mengalami nyeri hebat pada kala I apabila tidak diatasi dengan baik akan menimbulkan masalah lain yaitu meningkatnya kecemasan karena kurangnya pengetahuan dan belum ada pengalaman pada ibu primigravida saat menghadapi persalinan sehingga produksi hormon adrenalin meningkat dan mengakibatkan vasokonstriksi yang menyebabkan aliran darah ibu ke janin menurun. Janin akan mengalami hipoksia sedangkan ibu akan mengalami persalinan lama dan dapat meningkatkan tekanan sistolik dan diastolik.

Nyeri persalinan merupakan suatu kondisi yang fisiologis. Secara fisiologi nyeri persalinan mulai timbul pada persalinan kala I fase laten dan fase aktif. Nyeri berasal dari kontraksi uterus dan dilatasi serviks. Semakin bertambahnya baik volume maupun frekuensi kontraksi uterus, nyeri yang dirasakan akan bertambah kuat, puncak nyeri terjadi di mana pembukaan lengkap sampai $10 \mathrm{~cm}$ dan berlangsung selama 6 jam. Nyeri yang terjadi dapat mempengaruhi kondisi ibu berupa kelelahan, rasa takut, khawatir dan menimbulkan stres. Stres dapat menyebabkan melemahnya kontraksi rahim dan berakibat pada persalinan yang lama (Suririnah, 2014).

Nyeri persalinan ini dapat menyebabkan ibu lebih memilih alternative persalinan lain untuk menghindari nyeri persalinan tersebut yaitu Persalinan Sectio Caesarea. Menurut World Health Organitation (WHO), standar rata-rata sectio caesarea disebuah negara adalah sekitar $5-15 \%$ per 1000 kelahiran di dunia, rumah sakit pemerintah rata-rata $11 \%$, sementara di rumah sakit swasta bisa lebih dari 30\%. Adapun saat ini, permintaan sectio caesarea (SC) di sejumlah negara berkembang melonjak pesat setiap tahunnya (Judhita, 2015). Secara umum jumlah persalinan sectio caesarea (SC) di Indonesia adalah sekitar $30-80 \%$ dari total persalinan. RSUP Sanglah Denpasar Bali mencatat adanya peningkatan persalinan bedah SC dari tahun 2011 yang berjumlah $5,8 \%$ menjadi 14,8\% dari total persalinan di tahun 2016 . 
Manajemen nyeri persalinan dapat diterapkan secara non-farmakologis dan farmakolgis. Pendekatan secara nonfarmakologis tanpa menggunakan obatobatan seperti relaksasi, massage, akupresur, akupuntur, kompres panas atau dingin, dan aromaterapi, sedangkan secara farmakologis melalui penggunaan obatobatan. Pendekatan secara nonfaramakologis ini termasuk ke dalam asuhan komplementer yang dapat diberikan oleh bidan kepada klien bersalinnya. Hal tersebut juga merupakan kompetensi bidan yang dapat diberikan kepada pasiennya. Asuhan ini lebih aman, sederhana dan tidak menimbulkan efek merugikan serta mengacu kepada asuhan sayang ibu, dibandingkan dengan metode farmakologi yang berpotensi mempunyai efek yang merugikan. Menurut Sylvia T Brown (2010), yang bertujuan untuk melihat pengaruh metode non-farmakologi terhadap penurunan intensitas nyeri persalinan dengan 10 metode nonfarmakologi yang dilakukan pada 46 orang sampel diperoleh hasil bahwa teknik pernapasan, relaksasi, akupresur, massage merupakan teknik yang paling efektif di dalam menurunkan nyeri saat persalinan (Arifin, L., 2014). Hal tersebut sejalan dengan penelitian yang dilakukan oleh Nolan (2013) dimana dala penelian tersebut menyebautkan bahwa tubuh memiliki pereda nyeri alamiah yaitu endorphin. Endorphin bisa diperoleh dengan massage. Massage adalah melakukan tekanan pada tangan pada jaringan lunak tanpa menyebabkan gerakan atau perubahan posisi sendi untuk meredakan nyeri. Hanya 19,3\% wanita mendapat massage untuk meredakan nyeri dan hanya $5 \%$ bidan dilaporkan menggunakan metode ini. Ketidaksesuaian ini berlawanan dengan pemberian obat seperti petidin, yang dilaporkan $37,8 \%$ oleh bidan (Mander, R., 2013).
Dalam persalinan, massage secara lembut dapat membantu ibu lebih rileks dan nyaman selama persalinan. Sebuah penelitian menyebutkan ibu jika di massage 20 menit setiap jam selama tahapan persalinan yang dilakukan oleh petugas kesehatan, keluarga pasien ataupun pasien itu sendiri akan lebih bebas dari rasa sakit, karena massage merangsang tubuh melepaskan senyawa endorphin. Banyak bagian dari tubuh ibu bersalin yang dapat di massage seperti kepala, leher, punggung, dan tungkai. Namun pada saat memijat pemijat harus memperhatikan respon ibu apakah tekanan yang diberikan sudah tepat (Meiliasari, M., dan Danuatmaja, B., 2012).

Berdasarkan hasil studi pendahuluan yang dilaksanakan pada 18 Januari 2019 di PMB Putu Putrini, A.Md.Keb, peneliti memperoleh data pada bulan Januari 2019 terdapat ibu bersalin primigravida sebanyak 25 orang. Hasil wawancara dengan 10 orang ibu bersalin, sebanyak 7 orang mengatakan nyeri semakin berkurang apabila diberikan sentuhan seperti pijatan pada punggung oleh keluarga yang mendampingi, sebanyak 3 orang tidak suka diberikan pijatan pada punggung karena tidak nyaman jika disentuh.

Hal tersebut mengakibatkan peneliti tertarik untuk melakukan penelitian terkait pengaruh massage punggung yang merupakan salah satu asuhan komplementer bidan terhadap intensitas nyeri pada pasien ibu bersalin. Adapun tujuan dari penelitian ini adalah untuk mengetahui pengaruh dari kompetensi asuhan kebidanan komplementer yang dimiliki oleh bidan dalam massage punggung terhadap intensitas nyeri ibu bersalin.

\section{METODE PENELITIAN}

Study Design

Penelitian ini menggunaan desain penelitian Quasi Experiment dengan 
rancangan penelitian One Group pre-test dan post-test design. Adapun penelitian ini menguji adanya perubahan tingkat nyeri persalinan setelah diberikan massage punggung baik yang dilakukan pada satu kelompok tanpa adanya pembanding.

Research Subject

Penelitian ini menggunakan ibu bersalin primigravida sebagai subjek penelitiannya. Adapun subjek penelitian yang digunakan berdasarkan kriteria inklusi yakni bersalin di PMB Putu Putrini, A.Md.Keb, Primigravida, dn bersedia mendai responden. Metode sampling yang digunakan dalam penelitian ini adalah dengan menggunaan teknik accidental sampling.

Data Collection

Penelitian ini dilakukan pada Bulan Pebruari 2019 sampai dengan Maret 2019 dan dilakukan di PMB Putu Putrini, A.Md.Keb.

Instrument

Pengumpulan data dilakukan dengan menggunakan data primer melalui pemberian kuisioner dimana sebelumnya dilakukan pemberian informed Consent terlebih dahulu.

Variabel Penelitian

Variabel independent penelitian ini adalah pemberian massage.. Variabel independent penelitian ini adalah pemberian massage. Variabel dependent penelitian ini adalah tingkat rasa nyeri pada persalinan.

Data Analysis

Analisa data penelitian dilakukan pada tingkat kepercayaan $95 \%$ dengan program Statistical Product and Service Solution (SPSS). HO ditolak bila $p<0,05$ berarti ada pengaruh massage punggung terhadap pengurangan intesnitas nyeri pada ibu bersalin primigravida.

\section{HASIL PENELITIAN}

Pengumpulan data dilaksanakan pada tanggal 8 Pebruari 2019 samapai dengan 8 Maret 2019. Adapun hasil dari penelitian ini antara lain sebagai berikut :

\section{Table 1. Distribusi Responden Berdasarkan Tingkat Nyeri Persalinan Sebelum Diberikan Massage Punggung di PMB Putu Putrini, A.Md.Keb}

\begin{tabular}{lccc}
\hline No. & Tingkat Nyeri & Frekuensi (F) & Persentase (\%) \\
1. & Tidak Nyeri & 0 & 0 \\
2. & Nyeri Ringan & 0 & 0 \\
3. & Nyeri Sedang & 22 & 95,7 \\
4. & Nyeri Berat & 1 & 4,3 \\
5. & Nyeri Sangat Berat & 0 & 0 \\
\hline & Jumlah & $\mathbf{2 3}$ & $\mathbf{1 0 0}$ \\
\hline
\end{tabular}

Sumber : Data Primer Penelitian Bulan Februari - Maret Tahun 2019

Berdasarkan tabel 1 jelas terlihat jika sebagian besar responden memiliki nyeri sedang $(95,7 \%)$, sebagian kecil memiliki nyeri berat $(4,3 \%)$, dan tidak ada yang mengalami nyeri ringan.

Table 2 Distribusi Responden Berdasarkan Tingkat Nyeri Persalinan Sesudah Diberikan Massage Punggung di PMB Putu Putrini, A.Md.Keb 


\begin{tabular}{lccc}
\hline No. & Tingkat Nyeri & Frekuensi (F) & Persentase (\%) \\
1. & Tidak Nyeri & 0 & 0 \\
2. & Nyeri Ringan & 19 & 82,6 \\
3. & Nyeri Sedang & 4 & 17,4 \\
4. & Nyeri Berat & 0 & 0 \\
5. & Nyeri Sangat Berat & 0 & 0 \\
\hline & Jumlah & $\mathbf{2 3}$ & $\mathbf{1 0 0}$
\end{tabular}

Sumber : Data Primer Penelitian Bulan Februari - Maret Tahun 2019

Berdasarkan tabel 2 dapat dilihat jika sebagian besar 19 responden $(82,6 \%)$ mengalami nyeri ringan, 4 responden $(17,4 \%)$ mengalami nyeri sedang. Dan tidak ada responden yang mengalami tidak nyeri, nyeri berat, dan nyeri sangat berat

Table 3 Pengaruh Massage Punggung Terhadap Pengurangan Intensitas Nyeri Pada Ibu Bersalin Primigravida di PMB Putu Putrini

\begin{tabular}{lccccc}
\hline No. & Tingkat Nyeri & Pre & Post & Z & P Value \\
1. & Tidak Nyeri & 0 & 0 & & \\
2. & Nyeri Ringan & 0 & 19 & & \\
3. & Nyeri Sedang & 22 & 4 & & \\
4. & Nyeri Berat & 1 & 0 & & \\
5. Nyeri Sangat Berat & 0 & 0 & & \\
\hline Jumlah & $\mathbf{2 3}$ & $\mathbf{2 3}$ & $\mathbf{- 4 , 2 6 4}^{\mathbf{a}}$ & $\mathbf{0 , 0 0}$ \\
\hline
\end{tabular}

Sumber : Data Primer Penelitian Bulan Februari - Maret Tahun 2019

Berdasarkan Tabel 3, menunjukkan jika teknik massage punggung sangat efektif dalam menurunkan tingkat nyeri persalinan primigravida di PMB Putu Putrini dengan nilai $\mathrm{p}=0,00 \quad(\mathrm{p}<0,05)$ yang artinya $\mathrm{p}$ value $<0,05$, sehingga hipotesa nol ditolak dan hipotesa alternative dalam penelitian ini diterima, dimana berarrti ada pengaruh massage punggung terhadap pengurangan intensitas nyeri pada ibu beralin primigravida di PMB Putu Putrini, A.Md.Keb.

\section{PEMBAHASAN}

A. Intensitas Nyeri Pada Ibu Sebelum Diberikan Asuhan Komplementer Massage Punggung
Sebagian besar nyeri yang dirasakan oleh ibu bersalin primigravida disini dikarenakan terjadinya kontraksi yang semakin lama semakin sering dan terjadinya pembukaan servik yang semakin bertambah. Selain hal tersebut dalam menghadapi persalinan ibu juga merasa cemas dan takut yang dilihat dari mimik wajah saat peneliti melakukan observasi. Perasaan cemas dan takut juga akan mempengaruhi bertambahnya rasa nyeri pada ibu bersalin perimigravida. Nyeri persalinan yang terjadi pada responden merupakan suatu perasaan tidak menyenangkan yang merupakan respon individu dalam proses persalinan. Nyeri yang dialami responden dikarenakan adanya perubahan fisiologis dari jalan lahir 
dan rahim. Hasil ini didukung oleh teori Bandiyah, (2012), bahwa nyeri persalinan disebabkan oleh proses dilatasi servik, hipoksia otot uterus saat kontraksi, iskemia korpus uteri dan peregangan segmen bawah rahim dan kompresi saraf di servik. Nyeri yang terjadi karena adanya stres dalam menghadapi kehamilan dapat merangsang kontraksi uterus yang berlebihan. Kontraksi uterus yang tak terkendalikan akan menghantarkan rasa nyeri saat persalinan. Hasil penelitian ini didukung oleh penelitian Marpuah (2013), menunjukkan sebagaian besar nyeri persalinan yang dihadapi oleh ibu primigravida mengalami nyeri berat sebanyak 54\% mengalami nyeri sedang, dan sebanyak $46 \%$ mengalami nyeri ringan.

\section{B. Intensitas Nyeri Pada Ibu Sesudah Diberikan Asuhan Komplementer Massage Punggung}

Berdasarkan hasil observasi secara langsung peneliti memberikan teknik massage pada ibu bersalin primigravida setelah itu didapatkan hasil ibu yang awalnya mengalami nyeri berat menjadi berkurang. Hal tersebut dikarenakan adanya pengaruh pemberian massage punggung pada ibu bersalin primigravida. Dimana dengan diberikan teknik massage dengan cara rangsangan pada punggung ibu bersalin primigravida dengan melakukan usapan pada punggung dengan menggunakan telapak tangan selama ada kontraksi uterus (His) nyeri yang dirasakan ibu bersalin menjadi berkurang.

Salah satu management nyeri persalinan adalah dengan massage punggung. Massage punggung merupakan salah satu dari asuhan komplementer yang dapat diberikan oleh bidan. Asuhan Komplementer merupakan asuhan yang dapat diberikan oleh tenaga kesehatan khususnya dalam hal ini adalah bidan kepada pasien dengan menggunakan pendekatan holistik. Pendekatan holistik berarti pendekatan menyeluruh pada ibu dimana meliputi pendekatan bio psiko sosio spiritual dan kultural. Konsep holistik ini mengakibatkan bidan hatus mencari, menemukan, dan melakukan intervensi terhadap masalah/keluhan kesehatan sehingga dapat dikelola dengan baik dan dilakukan secara komprehensif. Prinsip pendekatan holistik dapat diwujudkan melalui asuhan sayang ibu dan bayi. Evidence based midwifery menunjukkan jika ibu diperhatikan dan diberi dukungan selama persalinan maka mereka akan mendapatkan rasa aman dan nyaman sehingga hasil yang didapat akan lebih baik. Penggunaan terapi komplementer pada perawatan maternitas dalam seperti massage punggung membantu mereka mengatasi ketidaknyamanan kehamilan dan persalinan.

Massage punggung merupakan teknik pereda nyeri yang banyak memberikan masukkan terbesar karena teknik relaksasi dalam persalinan dapat mencegah kesalahan yang berlebihan pasca persalinan. Adapun massage punggung selama proses persalinan dapat mempertahankan komponen system saraf dalam keadaan homeostasis sehingga tidak terjadi peningkatan suplai darah, mengurangi kecemasan dan ketakutan agar ibu dapat beradaptasi dengan nyeri selama proses persalinan (Rosemary, 2013).

Hasil penelitian ini senada pada penelitian Irawati (2012) yang menyatakan bahwa setelah dilakuakan massage pungguang terjadi penurunan intensitas nyeri yang dirasakan oleh responden. Kategori menyiksa berkurang dari 30\% menjadi $13,3 \%$ setelah dilakukan massage punggung, sedangkan untuk kategori tidak nyaman meningkat dari $6,7 \%$ menjadi $13,2 \%$. 


\section{Analisis Pengaruh Asuhan Komplementer Massage Punggung Terhadap Pengurangan Intensitas Nyeri Pada Ibu Bersalin Primigravida \\ Berdasarkan data penelitian} menunjukkan bahwa massage punggung efektif dalam menurunkan tingkat nyeri persalinan pada ibu bersalin primigravida di PMB Putu Putrini, A.Md.Keb. Hasil uji statistic juga didapatkan hasil $(\mathrm{p}<0,05)$ sehingga ada pengaruhnya massage punggung terhadap nyeri persalinan. Tingkat nyeri persalinan pada responden sesudah diberikan massage punggung mengalami penurunan jika dibandingkan sebelum diberi massage punggung.

Dengan diberikan teknik massage berarti ada pengaruh terhadap pengurangan intensitas nyeri pada ibu bersalin primigravida. Yang mana teknik massage dapat diberikan pada ibu inpartu kala I fase aktif disaat ada kontraksi, dimana lama pemberian massage dalam penelitian ini diberikan setiap 2 sampai 3 menit dan berlangsung selama $50-60$ detik. Dari pembukaan servik $4 \mathrm{~cm}$ sampai pembukaan servik $10 \mathrm{~cm}$. Disini peneliti mengobservasi secara langsung setiap ada kontraksi dengan cara memberikan teknik massage punggung pada ibu bersalin primigravida.

Hasil penelitian ini juga didukung oleh penelitian Insaffitan (2010), menunjukkan hasil bahwa diperoleh ratarata skala nyeri pada responden sebelum dilakukan massage punggung dan sesudah dilakukan massage punggung adalah berbeda secara signifikan. Rata-rata skala nyeri pada responden sebelum dilakukan massage $12,31 \%$ dan sesudah dilakukan massage skala nyeri rata-rata 4,69\%.

Persamaan hasil dari kedua penelitian tersebut terjadi karena massage punggung yang merupakan salah satu terapi non-farmakologi untuk menurunkan nyeri persalinan. Berdasarkan hal itulah massage punggung yang diberikan pada ibu bersalin dapat memperlancar aliran darah dengan merelaksasikan otot-otot yang mengalami spasme yang pada akhirnya akan menurunkan sensasi nyeri (Smeltzer \& Bare, 2011).

Menurut Mander (2013), massage punggung dapat menurunkan intensitas nyeri adalah teori Huges dkk (1976). Menurutnya dalam keadaan tertentu tubuh mampu mengeluarkan opoid endogen yaitu endorphin dan enkefalin. Zat-zat tersebut memiliki sifat mirip morfin dengan efek analgetik yang membentuk suatu system penekan nyeri. Massage punggung merupakan salah satu keadaan yang mampu merangsang tubuh untuk mengeluarkan opoid endogen sehingga terbentuk system penekanan nyeri yang akhirnya akan menyebabkan penurunan intensitas nyeri. Hal inilah yang menyebabkan adanya perbedaan penurunan intensitas nyeri sebelum dan sesudah dilakukan massage punggung, dimana setelah diberikan massage punggung terjadi penurunan intensitas nyeri.

\section{Kompetensi Bidan Dalam Asuhan Komplementer Massage Punggung Terhadap Pengurangan Intensitas Nyeri Pada}

Menilik Peraturan Menteri

Kesehatan Republik Indonesia Nomor 1464 Tahun 2010 tentang Ixin dan Penyelenggaraan Praktik Bidan menunjukkan jika bidan memiliki wewenang dalam melakukan asuhan kebidanan pada ibu bersalin. Bidan dalam melakukan wewenangnya memberikan asuhan pada ibu bersalin, mengakibatkan bidan terus berupaya untuk meningkatkan kompetensi yang dimiliknya. Apalagi tuntutan masyarakat saat ini dan gaung program pemerintah terkait dengan 
pelayanan kesehatan tradisional dimana pemberian pijatan merupakan salah satu bagian dari pelayanan kesehatan komplementer yang dapat diberikan pada masyarakat.

Hal tersebut berdasarkan pada Peraturan Menteri Kesehatan RI Nomor 61 Tahun 2016 tentang Pelayanan Kesehatan Tradisional. Adapun hal tersebut didukung dengan Standar Profesi Bidan yang diatur dalam Keputusan Menteri Kesehatan Rebublik Indonesia No 369/MENKES/SK/III/2007, dimana didalamnya yaitu terdiri dari 9 kompetensi bidan, dan Undang-Undang Kesehatan RI No 36 tahun 2014 Tentang Kesehatan Pasal 26 menyebutkan "Tenaga Kesehatan yang telah ditempatkan di fasilitas pelayanan kesehatan wajib melaksanakan tugas sesuai kompetensi dan kewenangannya". Kompetensi pertama adalah terkait tentang bagaimana seorang bidan dalam memberikan asuhan kebidanan harus sesuai dengan budaya setempat dan disesuaikan dengan pengetahuan dan keterampilan kebidanan. Pemberian pijatan pada ibu juga merupakan salah satu gerakan dari pemberian asuhan sayang ibu sehingga ibu akan merasa lebih diperhatikan sehingga nyeri pada ibu akan mengalami penurunan.

\section{SIMPULAN}

1. Sebelum diberikan massage punggung sebagian besar rasa nyeri yang dialami ibu bersalin primigravida adalah 22 responden $(95,7 \%)$ mengalami nyeri sedang dan 1 responden $(4,3 \%)$ mengalami nyeri berat.

2. Sesudah diberikan massage punggung sebagian besar rasa nyeri yang dialami ibu bersalin primigravida adalah 19 responden $(82,6 \%)$ mengalami nyeri ringan dan 4 responden $(17,4 \%)$ mengalami nyeri sedang.

3. Ada perbedaan yang signifikan antara sebelum dan sesudah diberikan massage punggung terhadap pengurangan intensitas nyeri pada ibu bersalin primigravida di PMB Putu Putrini, A.Md.Keb dengan hasil uji pvalue didapatkan hasil $(\mathrm{p}<0,05)$.

\section{SARAN}

$\begin{array}{ccr}\text { Bagi } & \text { bidan sebaiknya } \\ \text { mempromosikan penanganan nyeri }\end{array}$ persalinan dengan tanpa obat-obatan seperti massage punggung, hypnosis pendampingan suami kepada masyarakat luas dengan memberikan penyuluhan secara berkala pada ibu hamil agar memberikan salah satu metode tanpa obatobatan yang efektif dan mudah untuk mengurangi nyeri persalinan.

Bagi ibu hamil sebaiknya dapat melakukan salah satu cara penatalaksanaan management nyeri tanpa obat-obatan dengan memotivasi suami agar melakukannya secara kontinyu untuk dapat merespon nyeri persalinan dan persiapan persalinan sehingga dapat mengurangi nyeri saat persalinan.

\section{REFERENCES}

Aprillia, Y. (2017). Bebas Takut Hamil dan Melahirkan. Jakarta : Gramedia Pustaka Utama, 14-17, 97

Blandine Calais-Germain, N.V. (2009). Preparing For A Gentle Birth. Rochester New York : Healing Art Press, 108

Damayanti. (2014). Buku Ajar Asuhan Kebidanan Komprehensif Pada Ibu Dan Bayi Baru Lahir. Yogyakarta : CV Budi Utama, 24 
Diane M.Fraser dan Margaret A. Cooper. (2009). Myles Buku Ajar Bidan. Jakarta : EGC, 25, 32, 902

Endang Purwoastuti, E.S. (2015). Etikolegal Dalam Praktik Kebidanan. Yogyakarta : Pustaka Baru Press, 35-62

M. Yusuf Hanafiah dan Amri Amir. (2014). Etika Kedokteran Dan Hukum Kesehatan. Jakarta : EGC, 149

Oktarina, M. (2016). Asuhan Kebidanan Persalinan Dan Bayi Baru Lahir. Yogyakarta : Deepublish, 6-7

WHO. (2013). WHO Traditional Medicine Strategy 2014-2023. Geneva : World Health Organizaion, 33 